\title{
JUSTIÇA RESTAURATIVA NO CONTEXTO UNIVERSITÁRIO: ESTUDO DE CASO DA UNIVERSIDADE DALHOUSIE- CA
}

Versão original

TESE DE DOUTORADO

Orientador: Dr. Guilherme Assis de Almeida

UNIVERSIDADE DE SÃO PAULO

FACULDADE DE DIREITO

SÃO PAULO - SP 


\section{JUSTIÇA RESTAURATIVA NO CONTEXTO UNIVERSITÁRIO: ESTUDO DE CASO DA UNIVERSIDADE DALHOUSIE- CA}

Tese apresentada à banca examinadora do Programa de Pós-Graduação em Direito, da Faculdade de Direito da Universidade de São Paulo, como exigência parcial para obtenção do título de Doutora em Direito, na área de concentração Direitos Humanos, sob a orientação do professor Dr. Guilherme Assis de Almeida.

UNIVERSIDADE DE SÃO PAULO

FACULDADE DE DIREITO

São Paulo - SP 
Boin Aguiar, Carla Maria Zamith

Justiça Restaurativa no contexto

universitário: estudo de caso da Universidade

Dalhousie- CA /Carla Maria Zamith Boin Aguiar;

orientador Guilherme Assis de Almeida. - São

Paulo, 2019.

$184 \mathrm{f}$.

Tese (Doutorado) - Programa de Pós-graduação

em Direito, da Faculdade de Direito da

Universidade de São Paulo. Área de concentração:

Direitos Humano

1. Justiça Restaurativa. 2. Direitos Humanos. 3. Misoginia. 4. Cultura do Estupro 
BOIN AGUIAR, Carla Maria Zamith. JUSTIÇA RESTAURATIVA NO CONTEXTO UNIVERSITÁRIO: ESTUDO DE CASO DA UNIVERSIDADE DALHOUSIE - CA. 2019. 184f. Tese (Doutorado). Faculdade de Direito, Universidade de São Paulo, São Paulo, 2019.

Aprovada em:

Banca Examinadora:

Prof. Dr: Instituição:

Julgamento: Introdução:

Prof. Dr: Instituição:

Julgamento: Introdução:

Prof. Dr: Instituição:

Julgamento: Introdução:

Prof. Dr: Instituição:

Julgamento: Introdução:

Prof. Dr: Instituição:

Julgamento: Introdução: 
Para meus pais Celso e Isabel, minhas bases;

Gabriela, Victória, André e Nina, meus nortes. 


\section{Agradecimentos}

Ao professor e orientador Guilherme Assis de Almeida, agradeço pela confiança, por ter acreditado em minha capacidade de pesquisa, pelo apoio, ajuda e orientação durante todos estes anos.

Aos Professores Andrea Rabinovici e Zysman Neiman sou imensamente grata pelos laços de amizade que nos unem, pela ajuda e confiança que sempre depositaram em meu trabalho. Me sinto honrada de ter podido contar com o apoio de vocês ao longo destes anos de estudo do doutorado.

Professor João Salm, obrigada pela ajuda incondicional desde a primeira troca de e-mails que fizemos no final de 2015, pelas conversas esclarecedoras ao longo do período da escrita, me apoiando e incentivando sempre. Pela generosidade de me apresentar os professores George Pavlich e Gerry Jonhstone, com os quais tive grande identificação de ideias. Hoje mais que professor e exemplo de profissional, considero-o um grande amigo.

Ao professor George Pavlich pela expressão real do sentido de 'hospitalidade' termo tão caro a ele a à Justiça Restaurativa- por meio do acolhimento em minha visita a Edmonton, das conversas elucidativas estabelecidas durante o dia todo de sua visita a São Paulo.

A Fernando Aguiar agradeço pelo companheirismo e apoio durante o longo período de estudo e prática que antecederam meu sonho de fazer o doutorado.

À minha família Celso Boin, Isabel Boin, Gabriela Boin Aguiar, Daniel Tramonte, Victoria Boin Aguiar, Celso Boin Junior, Alessandra Boin, Creusa Afonso de Almeida, Manoel Afonso de Almeida, Manoel Afonso de Almeida Filho, Simone Afonso de Almeida, Francisco Afonso de Almeida e Renata Afonso de Almeida, me faltam palavras para expressar o carinho e gratidão que sinto por todos vocês, de uma forma ou de outra vocês fazem parte desse trabalho.

Stelio de Carvalho Neto, muito obrigada pelas conversas inspiradoras, pela motivação, pela ajuda na organização das ideias e pelo apoio no momento difícil de final da escrita da tese. 
A compensação consiste, portanto, em um convite e um direito à crueldade.

Friedrich Nietzsche, Genealogia da Moral, segunda dissertação, seção 5 


\section{RESUMO}

BOIN AGUIAR, Carla Maria Zamith. JUSTIÇA RESTAURATIVA NO CONTEXTO UNIVERSITÁRIO: ESTUDO DE CASO DA UNIVERSIDADE DALHOUSIE - CA. 2019. 184f. Tese (Doutorado). Faculdade de Direito, Universidade de São Paulo, São Paulo, 2019.

Podemos considerar que a Justiça Restaurativa encontra-se na fase de maturidade e requer novas formas de pensar sobre seu processo identitário. É sabido que se fundamenta em um paradigma de justiça diferente do convencional e vem provocando debates calorosos com relação a sua definição e conceituação. Diante desse cenário, a presente tese objetiva desenvolver uma análise crítica do projeto-piloto de Justiça Restaurativa implantado na Universidade Dalhousie, considerando o processo restaurativo instaurado para tratar do caso de misoginia em rede social (Facebook) que ficou conhecido como o Dentistry Case, por oferecer elementos e características essenciais para o desenvolvimento de reflexões, investigações e críticas com relação às práticas restaurativas, enquanto via de realização dos direitos humanos na contemporaneidade. A análise será feita com base na verificação das diferentes raízes históricas que antecedem o movimento restaurativo e a diversidade de contextos de aplicação que vão além do sistema de justiça. Em consonância com referenciais teóricos e práticos da Justiça Restaurativa, sobretudo a partir dos entendimentos de temas sensíveis desenvolvidos por George Pavlich, como: paradoxos que envolvem as chamadas "governamentalidades restaurativas", impossibilidade de termos princípios gerais universais capazes de fundamentarem a Justiça Restaurativa, e, atenção às racionalidades e linguagens que permeiam os contextos de sua aplicação.

Palavras-chave: justiça restaurativa, misoginia, direitos humanos, mediação 


\begin{abstract}
BOIN AGUIAR, Carla Maria Zamith. RESTORATIVE JUSTICE IN THE UNIVERSITY

SETTING: A CASE STUDY FROM DALHOUSIE UNIVERSITY - CANADA, 2019. 184f. Thesis (Ph.D.). School of Law, Universidade de São Paulo, São Paulo, 2019.
\end{abstract}

We can consider that Restorative Justice is in a matured phase and requires new forms of thinking about its identity consolidation. It is well-established that Restorative Justice is grounded in a paradigm of justice distinct from the traditional one and has been causing heated debate as far as its definition and concepts are concerned. In light of this scenario, this thesis aims to develop a critical analysis of the Pilot Restorative Justice Project implemented at Dalhousie University, considering the restorative process installed to address the misogyny case in a social network (Facebook), which became known as the Dentistry Case, as it offers elements and characteristics essential to induce reflections, investigation and critiques of the restorative practices as a means of enforcement of human rights in contemporary times. The analysis will be made based on the survey of the different historical roots that precede the restorative movement and the diversity of application contexts, which span far beyond the justice system, and in consonance with the theoretical and practical references of Restorative Justice, particularly those emanating from sensitive aspects studied by George Pavlich, such as the paradoxes involving the so-called "restorative governmentalities", the impossibility of having universally-accepted general principles capable of affording the fundamentals for Restorative Justice, and attention to the rationalities and languages underlying the settings of its application.

Key words: restorative justice, misogyny, human rights, mediation 


\section{SUMÁRIO}

INTRODUÇÃO .11

PARTE I - JUSTIÇA RESTAURATIVA E SEUS DESAFIOS CONTEMPORÂNEOS

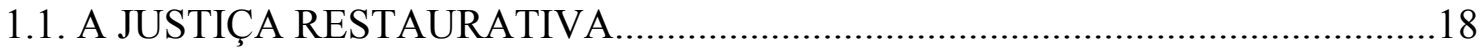

1.1.1. Antecedentes históricos, contextos e aproximação....................................... 18

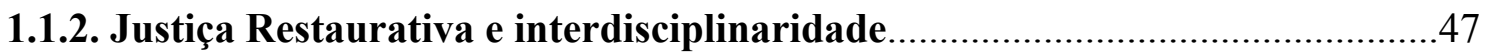

1.2. A JUSTIÇA RESTAURATIVA NA CONTEMPORANEIDADE...........................51

1.2.1. Justiça Restaurativa e Direitos Humanos....................................................52

1.2.2. Justiça Restaurativa, paradoxos e princípios gerais universais: a obra de George Pavlich.

PARTE II - JUSTIÇA RESTAURATIVA NO CONTEXTO UNIVERSITÁRIO

2.1. O PROJETO-PILOTO DE JUSTIÇA RESTAURATIVA DA UNIVERSIDADE

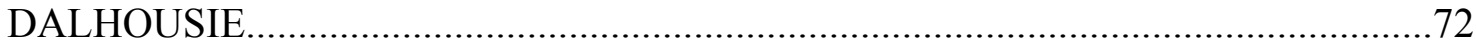

2.1.1. Processo de idealização, implantação e diretrizes do projeto- piloto ............76

2.1.2. Efeitos e resultados alcançados pelo projeto-piloto.......................92

2.2. QUESTÃO DE GÊNERO - CASO DE ASSÉDIO NA FACULDADE DE ODONTOLOGIA DA UNIVERSIDADE DALHOUSIE.............................. 108

2.2.1. Síntese dos acontecimentos e princípios éticos seguidos durante o processo

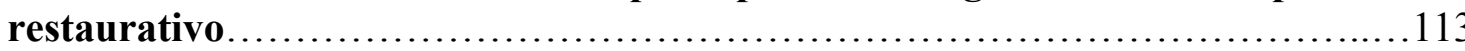

2.2.2. Efeitos e resultados alcançados pelo processo restaurativo no caso de assédio da faculdade de odontologia....................................................147

2.2.3. Conclusões com relação ao projeto-piloto e ao caso de assédio....................152

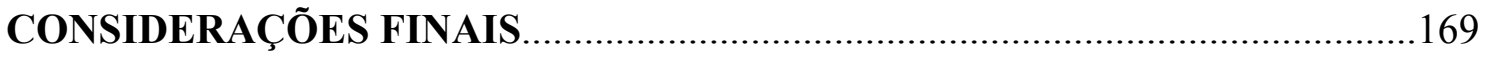

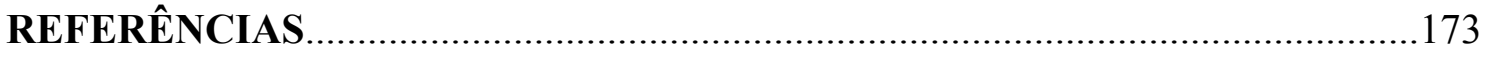

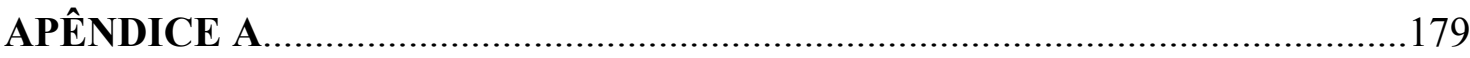




\section{INTRODUÇÃO}

Esse trabalho de doutorado foi construído com o intuito de analisar e questionar as formas com que se pensa a Justiça Restaurativa enquanto via de realização dos direitos humanos na contemporaneidade. Nele, proponho reflexões sobre as práticas restaurativas entendidas como um movimento social para além do sistema criminal. Investigando contextos de aplicação de programas e projetos, e analisando conceituações desenvolvidas por autores que tratam esse tema, ressalto os pontos tratados pelo sociólogo George Pavlich ${ }^{1}$ : os paradoxos que envolvem as chamadas "governamentalidades restaurativas" ${ }^{2}$ a impossibilidade de estabelecermos princípios gerais universais para fundamentação da Justiça Restaurativa; a atenção às racionalidades e linguagens que permeiam os contextos de sua aplicação.

É fato que a Justiça Restaurativa parte de um paradigma de justiça diverso do que o proposto pelo sistema de justiça penal convencional: ela propõe a noção de restauração, reparação e cura ${ }^{3}$. Todavia se coloca em um terreno de difícil construção conceitual por demandar de seus praticantes uma postura de não-saber que diverge radicalmente da postura de autoridade requerida dos integrantes de instituições como o Poder Judiciário.

\footnotetext{
${ }^{1}$ Ele ocupa a cadeira de pesquisador em Teoria Social, Cultura e Direito no Canadá, é professor de Direito e Sociologia, na Universidade de Alberta. Escreveu extensivamente sobre as teorias social e legal, autor dos livros Justice Fragmented: Mediation Community Disputes Under Postmodern Conditions, Critique and Radical Discourses on Crime e Governing Paradoxes of Restorative Justice, entre outros. Coeditor dos livros Sociology for the Asking e, Law, Society and Governance: Foucault's Bequest. É considerado um dos críticos mais importantes da mediação comunitária e das práticas da Justiça Restaurativa. Além da leitura de artigos e livros, tive oportunidade de conhecer as ideias e críticas de George Pavlich sobre Justiça Restaurativa em conversas informais na cidade de Edmont, no Candá, em 2016, e, no Brasil, nas cidades de Curitiba e São Paulo, nos anos de 2016 e 2018, respectivamente.

${ }^{2}$ Conceito adotado por George Pavlich, mobilizando a noção de governamentalidade concebida por Focault, para designar as possíveis "mentalidades" existentes nos diversos programas de Justiça Restaurativa (PAVLICH, 2005, p.10).

${ }^{3}$ Encontrei uma boa ilustração desse entendimento da Justiça Restaurativa numa proposta de justiça preparada em 1989, pela Sandy Lake First Nation, um distrito de Oji-Cree, comunidade no noroeste de Ontário. "Provavelmente, uma das falhas mais sérias no sistema é a percepção diferente sobre o mal feito e como é melhor tratá-lo. Na comunidade não indígena, cometer um crime parece significar que o indivíduo é uma má pessoa e, portanto, deve ser punido. As comunidades indígenas percebem o mal feito como um mau comportamento que requer ensino ou uma doença que requer cura.". (ROSS, 1946, p.5)
} 
Tenho como objetivo explicitar os pontos críticos da Justiça Restaurativa e encará-los de frente, com seriedade e lucidez para refletirmos sobre o que precisa ser feito para conseguirmos construir, desconstruir e reconstruir conjuntamente formas de pensar e atuar coerentes com a proposta da restauração de danos. A noção de justiça deve ser estabelecida na particularidade da situação de conflito e refletir a percepção do justo das pessoas envolvidas em cada contexto vivenciado.

Esta tese resulta de pesquisas e estudos realizados desde a escrita da minha dissertação de Mestrado - acerca da Mediação e da Justiça Restaurativa - e, da atuação como professora, mediadora e facilitadora de círculos restaurativos ao longo dos últimos 15 anos. Em abril de 2005, participei do "I Simpósio Brasileiro de Justiça Restaurativa: Um braço da Cultura de Paz”, em Araçatuba (SP), como organizadora e facilitadora de rodas de diálogos. Essas experiências me permitiram observar uma variedade de nuances sobre os programas desenvolvidos dentro e fora do sistema judiciário, sob a denominação "Justiça Restaurativa".

$\mathrm{O}$ interesse em pesquisar projetos de Justiça Restaurativa realizados em Universidades surgiu a partir da constatação da relevância de estudar e compreender o desenvolvimento da Justiça Restaurativa fora do sistema judiciário: o contexto universitário, enquanto comunidade de aprendizagem, espaço de trocas de conhecimentos, possíveis mudanças de comportamentos, hábitos e pensamentos ideológicos, se revelou proficiente na aplicação de práticas que visam transformação radical.

A partir de 2015, me aproximei das iniciativas da Universidade Federal de São Paulo - Unifesp na busca por aprimorar suas políticas de direitos humanos e tratamento de conflitos através de práticas de Justiça Restaurativa. Nessa aproximação, tive a oportundade de realizar círculos restaurativos com os alunos para tratar conflitos institucionais que surgiram por conta do uso do espaço da universidade para realização de festas e de uma acusação de assédio sexual, problemas comuns em contextos universitários. Essa experiência foi fundamental para a formulação das questões que orientam a pesquisa que ora apresento.

Neste trabalho abordarei os debates travados entre teóricos e práticos sobre a definição do que seria Justiça Restaurativa. Mostrarei que muitas vezes, abordagens lineares, binárias e reducionistas acabam produzindo argumentações que só reforçam contradições e desentendimentos. 
Verifiquei que ora se alega a importância de que se estabeleçam regras claras que orientem as práticas restaurativas, ora se busca a construção de teorias que possam dar conta da tarefa de estruturar a Justiça Restaurativa como um sistema capaz de suplantar o sistema de justiça convencional; ora se tem o desejo de criar mais programas restaurativos vinculados às categorias de pensamento do sistema criminal que se opõem, ora se alega a cooptação estatal destes programas; ora se pretende justificar sua prática a partir de preceitos de cunho religioso, partindo para um campo dogmático moralista.

Como exemplo, temos, Gerry Johnstone e Daniel Van Ness, no livro Manual de Justiça Restaurativa, chamando a atenção para as inúmeras concepções antagônicas que orientam tanto a coneituação, quanto a delimitação dos contornos e enquadramentos dos modelos considerados Justiça Restaurativa:

(...) não é simplesmente porque as pessoas utilizam os termos de maneiras diversas em diferentes contextos. Pelo contrário, alguns proponentes da justiça restaurativa afirmam ou implicam que a forma que utilizam o conceito é o único apropriado, e que usar o conceito de justiça restaurativa para denominar práticas ou agendas que não são restaurativas cria confusões. Essas asserções podem ser feitas com tanta paixão que elas assumem "o tom de uma disputa bizarra entre crenças dentro de alguma seita religiosa obscura". (BAZEMORE E SCHIFF 2004: 51; cf. MCCOLD 2004a apud JOHNSTONE, 2007, p. 6$)^{4}$

Os autores se referem ao artigo de Paul Mccold, "Paradigm Muddle: The Threat to Restorative Justice Posed by Its Merger with Community Justice", que critica de forma contundente a fusão entre Justiça Restaurativa e justiça comunitária estabelecida por Gordon Bazemore e Mara Schiff: para ele, na medida em que o paradigma atual ainda é um modelo precário, essa fusão só pode produzir confusão. Bazemore e Shif reagem a essas críticas no artigo "Paradigm Muddle or Paradigm Paralysis? The Wide and Narrow Roads to Restorative Justice Reform (or, a Little Confusion May Be a Good Thing)"5 (BAZEMORE ET SHIF, 2007).

Não me deterei nas particularidades dessa discussão porque pretendo me concentrar no tratamento da distinção entre as diversas racionalidades que orientam

\footnotetext{
${ }^{4}$ Tradução livre da autora. No original: "Moreover, it is not simply that people use the term in diferente ways in diferente contexts. Rather, some proponentes of restorative justice assert or imply that their use of the concept is the only proper one, and that to use the concept in a diferente way is to create of restorative justice by applying it to practices or agendas which are not restorative. These assertions can bem ade with such a passion that they take on "the tone of a weird inter-faith squabble in an obscure religious sect"'. (BAZEMORE AND SCHIFF 2004: 51; cf. MCCOLD 2004 a apud JOHNSTONE, 2007, p. 6)

${ }^{5}$ Tradução livre da autora: "Confusão Paradigmática ou Paralisia Paradigmática? As estradas largas e estreitas para a reforma da justiça restaurativa (ou, uma pequena confusão pode ser uma coisa boa) (BAZEMORE ET SHIF, 2007)
} 
as práticas de gestão de conflitos: busco novas delimitações para o campo das práticas ditas restaurativas. Por ora, não estou interessada em distinções meramente descritivas: meu objetivo é encontrar traços identitários das racionalidades que orientam a Justiça Restaurativa.

As críticas e desafios apontados de lado a lado, demonstram certa inabilidade tanto dos estudiosos, quanto dos práticos, para lidar com uma proposta que demanda flexibilidade, abertura e compreensão da fragilidade de qualquer tentativa que vise estabelecer cálculos exatos sobre o conceito de justiça.

Apoiada nas formulações de Émile Durkheim, me parece ser possível afirmar que os intelectuais ${ }^{6}$ podem atuar de maneira cada vez mais importante e influente nas teorizações ligadas à Justiça Restaurativa, na medida em que podem desempenhar o papel de estudiosos e alargadores da inteligência, atuando como catalisadores e facilitadores de diálogos capazes de congregar experiências e conhecimentos oriundos da comunidade e das instituições que vêm se disponibilizando para desenvolver projetos restaurativos, como as universidades e inúmeras entidades públicas que integram o sistema judiciário.

Ao tomar conhecimento do projeto-piloto de Justiça Restaurativa implantado pela Universidade Dalhousie, identifiquei a importância de realizar uma pesquisa mais aprofundada sobre esse projeto, a fim de elaborar meus desenvolvimentos teóricos com base em um caso efetivo.

Encontrei pessoalmente Jacob Macisaac e Melissa Mackay, responsáveis pelo projeto, que relataram detalhadamente o processo restaurativo que aconteceu por dois anos para tratar o que ficou conhecido como Dentistry Case: um caso de misoginia em rede social (Facebook) envolvendo alunos, professores e funcionários da Faculdade de Odontologia da Universidade Dalhousie e a comunidade de Halifax. Este caso teve grande repercussão nacional e internacional, mobilizou a comunidade ao redor da Universidade, gerando críticas por parte de estudiosos do tema, de movimentos feministas e da comunidade canadense como um todo, conforme será relatado na Parte II do meu trabalho.

\footnotetext{
${ }^{6}$ Notemos brevemente que essa palavra, bastante cômoda, não tem de forma alguma o sentido impertimente que se lhe atribuiu maldosamente. $O$ intelectual não é aquele que tem o monopólio da inteligência: não há funções sociais em que a inteligência não seja necessária. Mas há aquelas onde ela é, ao mesmo tempo, o meio e o fim, o instrumento e o objetivo; emprega-se nelas a inteligência para alongar a inteligência, ou seja, para enriquecê-la com conhecimentos, ideias ou novas sensações. Ela é assim o todo dessas profíssões (arte, ciência), e é por exprimir essa particularidade que se chegou muito naturalmente a chamar de intelectual o homem que a ela se dedica. (DURKHEIM, 2016, p.39)
} 
A partir desse caso, percebi a abrangência do projeto-piloto de Justiça Restaurativa da Universidade, que engendrou inúmeros elementos para a realização de pesquisas, reflexões e análises críticas relevantes para o estudo, o entendimento e o aprendizado da Justiça Restaurativa.

Minha tese será apresentada em duas partes, cada uma com dois capítulos. $\mathrm{Na}$ primeira parte, A Justiça Restaurativa, farei uma exposição dos antecedentes históricos, abordando as "raízes" da Justiça Restaurativa, com o intuito de ressaltar a diversidade que fundamenta as práticas chamadas "restaurativas".

Os modelos mais conhecidos são: mediação vítima-ofensor (victim ofender mediation), conferência (conferencing), círculos de pacificação (peacemaking circles), círculos decisórios (sentencing circles), restituição (restitution), e círculos de construção de paz (peacemaking circles). Essas práticas têm sido implementadas em diversos contextos, suscitando reflexões, discussões e pesquisas acadêmicas a respeito da viabilidade de se desenvolver definições conceituais que as fundamentem e diferenciem.

Analisarei a existência de um movimento global que passou a ser conhecido como Justiça Restaurativa, e que vem se desenhando ao longo dos últimos cinquenta anos a partir da valorização dos conhecimentos oriundos das práticas ancestrais de auto composições (tribais, comunais e religiosas), pelos movimentos de acesso à justiça, somada ao crescimento do uso das chamadas ADRs- alternative dispute resolutions, e ao envolvimento da Organização das Nações Unidas.

Proporei reflexões sobre a importância de ampliarmos nossa visão sobre a possibilidade de implantação da Justiça Restaurativa em diferentes contextos, investigando os efeitos engendradas pela linguagem impregnada da racionalidade punitiva presente no pensamento moderno que impera nas instituições.

Na seção Justiça Restaurativa e interdisciplinaridade, chamo a atenção para a importância do desenvolvimento de pesquisas e estudos interdisciplinares que promovam abertura para reflexões sobre a complexidade que envolve as relações humanas e suas interações com o meio ambiente, visando oferecer aportes teóricos e 
práticos que revelem a dimensão filosófica que permeia o fenômeno que temos chamado de Justiça Restaurativa.

No capítulo A Justiça Restaurativa e a Idade Contemporânea, investigarei os desafios apresentados pelas racionalidades estabelecidas nos ambientes e contextos destinados à realização das práticas restaurativas. Para tanto, apresentarei um ensaio a partir da realização de uma analogia entre a Justiça Restaurativa e a noção de pensamento "rizomático" elaborada por Deleuze e Guattari. A proposta é a geração de modelos de pensamento que possam dar conta da complexidade que acompanha as práticas restaurativas enquanto instrumentos de realização dos direitos humanos na contemporaneidade.

Apresentarei a dicotomia que toma conta das discussões correntes sobre as práticas restaurativas colocando, de um lado, o sistema de punição imposto pelo Estado moderno e, do outro, as formas não estatais consideradas restaurativas, como aquelas presentes nas sociedades indígenas e comunais. Aqui, o desafio será alcançar noções de justiça que vão além daquilo que o positivismo jurídico contempla.

Vale ressaltar que minha proposta não é desenvolver um raciocínio que repita a lógica do antagonismo e da dualidade excludente, com elaborações e argumentações construídas para defender as práticas restaurativas em detrimento das práticas ora existentes no sistema judicial. Sigo o entendimento de que Justiça Restaurativa abarca práticas que transpassam o Poder Judiciário, e que tanto dentro quanto fora deste contexto, pode apresentar o paradoxo que envolve as chamadas "governamentalidades restaurativas" e o dilema do "imitador" identificados por George Pavlich, e tratados no item Justiça Restaurativa, paradoxos e princípios gerais universais: A obra de George Pavlich.

Pavlich afirma que a Justiça Restaurativa defende um processo radicalmente diferente do sistema de justiça criminal e acredita ter encontrado um paradoxo na tentativa de se estabelecer a Justiça Restaurativa dentro do sistema de justiça criminal. Ele argumenta que a Justiça Restaurativa, em certo sentido, será irrealizável caso se busque constituir sua identidade divergindo em grande parte das próprias instituições a que se mantém atrelada, e que de alguma forma procura reformar ou alterar.

O sociólogo canadense afirma que a ética da Justiça Restaurativa trata das diferentes possibilidades de estar com os outros, possibilidades essas que serão 
vivenciadas em situações imprevisíveis por meio de diálogos e negociações realizadas no momento em que acontecerem os processos restaurativos. Dessa forma defende que não há como predefinirmos princípios gerais absolutos para lidar com situações que ainda estão por vir. Se fizéssemos isso, correríamos o risco de impor um regime totalitário a uma prática que visa a flexibilização dos enquadramentos do pensamento moderno.

Por isso, entendo que a proposta de reflexão sobre o desenvolvimento da Justiça Restaurativa na contemporaneidade demanda a criação de mais espaços físicos e virtuais de diálogos entre os vários atores: pesquisadores, estudiosos e autores que se dedicam à delimitação teórica da Justiça Restaurativa, junto daquelas que estão diretamente envolvidas com a realização dessas práticas.

$\mathrm{Na}$ segunda parte do trabalho, meu objetivo será desenvolver uma análise crítica do projeto-piloto de Justiça Restaurativa implantado na Universidade de Dalhousie, considerando o processo restaurativo instaurado para tratar o Dentistry Case, tomando como base os referenciais teóricos e práticos da Justiça Restaurativa explicitados nos capítulos anteriores, em especial os pontos desenvolvidos por George Pavlich.

Buscarei demonstrar a necessidade de realizarmos deslocamentos e rupturas com certas premissas adotadas pela ciência jurídica para avançarmos na compreensão das experiências que vêm sendo realizadas no campo da Justiça Restaurativa. Para tanto, analisarei o projeto-piloto no item $O$ projeto-piloto de Justiça Restaurativa da Universidade Dalhousie, dividindo o conteúdo da seguinte forma: Processo de idealização, implantação e diretrizes do projeto-piloto e Efeitos e resultados alcançados pelo projeto-piloto. O "Dentistry Case" será tratado no item Questão de gênero: caso de assédio na Faculdade de Odontologia da Universidade Dalhousie.

Demonstrarei que o processo restaurativo no caso de assédio da Faculdade de Odontologia contou com procedimentos coerentes com as demandas colocadas por George Pavlich, com resultados satisfatórios, como se verificará na declaração pública dos alunos que participaram do processo (Vide Apêndice A).

A partir do estudo realizado atribuímos estas conquistas ao fato dessa experiência ter sido realizada fora do contexto do judiciário, e por fazer parte de uma instituição comprometida com pesquisas e práticas da Justiça Restaurativa. 


\section{CONSIDERAÇÕES FINAIS}

Ao longo da pesquisa e escrita da tese pude constatar que quando falamos sobre Justiça Restaurativa nos colocamos em um terreno pantanoso, no qual nos movemos com dificuldade, travada por ideias pré concebidas sobre conceitos como justiça, comunidade e punição. Como disse na introdução, o estudo da Justiça Restaurativa requer a assunção de um não-saber, a fim de que se engendre uma disposição de abertura para reflexões e críticas constantes.

$\mathrm{O}$ fato de perceber a necessidade de flexibilidade e abertura na forma de pensar sobre essas práticas não dispensa o esforço de formulação de norteadores que orientem o trabalho da Justiça Restaurativa. Por esta razão, recorri à proposta da interdisciplinaridade, da analogia com o pensamento rizomático (Deleuze e Guatarri), e aos estudos desenvolvidos por pesquisadores que se debruçam sobre o tema, especialmente George Pavlich, que faz críticas relevantes sobre a instauração de práticas da Justiça Restaurativa partindo da experiência.

Foi possível verificar que por se tratarem de práticas que partem de diferentes raízes históricas, elas trazem consigo uma diversidade de concepções no tratamento de relações conflituosas. No momento de implantação dos programas de Justiça Restaurativa há que se ter em mente os efeitos dessa implantação em cada contexto particular. A noção de Justiça Restaurativa se estabelece na relação entre as pessoas e o contexto em que se encontram, e por essa razão não é possível a definição de princípios gerais para serem seguidos de forma rígida por todo e qualquer programa.

Acredito que a união dos conceitos justiça e educação, que fundamentaram o projeto-piloto de Justiça Restaurativa da Universidade Dalhousie, abriu perspectivas para reflexões importantes sobre o que vêm a ser os direitos humanos na contemporaneidade, e em que medida as práticas restaurativas presentes nos contextos institucionais - ainda impregnados pela racionalidade binária, punitivista e excludente - podem fortalecer e viabilizar sua efetivação.

O estudo do caso de misoginia na rede social Facebook revelou os reflexos da noção punitivista que sustenta o sistema penal e o modo da grande maioria das pessoas pensarem sobre o conceito de justiça. As alunas sofreram inúmeras críticas ao longo do processo por optarem pelo encaminhamento do caso pela via da Justiça Restaurativa. No entanto, se mantiveram firmes com a escolha que fizeram, chegando a se posicionar, em algumas situações, em defesa dos alunos, o que acabou 
gerando maior união e comprometimento por parte de todos os envolvidos, conforme relatado na declaração dos Participantes do Processo de Justiça Restaurativa, publicada em $1^{\circ}$ de março de 2015 . (Apendice A)

As estudantes entenderam que as atitudes dos colegas de classe fizeram parte de um contexto maior. Por isso, não acharam que uma punição, dirigida apenas aos alunos autores dos posts, poderia dar conta da dimensão das sutilezas existentes naquela situação. Perceberam que o comportamento dos rapazes fazia parte de uma cultura patriarcal que ainda impera nos contextos universitários de praticamente todo o mundo. Constatamos casos de assédio e violência contra mulheres em Universidades nos Estados Unidos, Austrália, Reino Unido e Brasil. Conforme mencionado, o relatório de 311 páginas ${ }^{182}$ sobre assédio sexual, lançado no dia 13 de junho de 2018, pelas Academias Nacionais de Ciências, Engenharia e Medicina dos Estados Unidos, $20 \%$ das alunas de engenharia e mais de $40 \%$ das de medicina relataram já terem sofrido algum tipo de assédio sexual.

Ao repensar "o que é justo", as alunas optaram por uma visão que implica num senso de justiça que acolhe a alteridade, "nunca retratando o presente como necessário, visto que qualquer presente é sempre constituído pela sua conexão com o outro" (PAVLICH, 2002, p. 99). A partir dessa perspectiva, a demanda por justiça não se pautou pela compensação de um dano causado através da imposição de sofrimento ao responsável.

Pela declaração dos alunos, autores dos posts, constatamos que os efeitos causados pelo processo restaurativo foram mais abrangentes do que a aplicação de uma punição:

\footnotetext{
....Em todo o processo restaurativo, estamos realizando trabalho necessário para lamentar com sinceridade, confrontar os males que causamos, aceitar nossa responsabilidade e descobrir o que é preciso para que possamos nos corrigir e angariar o conhecimento, habilidades e capacidade de despertar confiança como profissionais de saúde. Essa é uma tarefa custosa e longa - e é assim que deve ser. Assumimos o compromisso de vê-la concluída. O processo envolveu membros da faculdade, da universidade, da profissão e do público. O envolvimento desses grupos prosseguirá e o ampliaremos à medida que o processo avance, de modo a examinar em detalhes as circunstâncias, causas e consequências mais abrangentes desta situação. Já aprendemos muito sobre nós
}

182 BELLUCK, P. "Ações para evitar assédio na universidade falharam e precisam mudar, diz relatório". In: Folha de S. Paulo. 14/06/2018. Publicado originalmente no The New York Times. Disponívelem:https:/www1.folha.uol.com.br/ciencia/2018/06/acoes-para-evitar-assedio-nauniversidade-falharam-e-precisam-mudar-diz-relatorio.shtml.Acesso em: 24 nov. 2018. http://revistapesquisa.fapesp.br/2018/07/05/para-enfrentar-o-assedio-sexual-na-academia/ 
mesmos, os resultados de nossas ações e nossa contribuição para a cultura e o ambiente na faculdade e na universidade. Nosso trabalho envolveu: a prestação de contas detalhadas de nossa participação no grupo do Facebook e nos eventos que se seguiram à sua revelação como parte do contato regular com os facilitadores restaurativos desde dezembro (pelo menos uma vez por semana e, em muitos casos, diariamente), participação em reuniões periódicas e contínuas com os facilitadores individualmente, em pequenos grupos e com todo o grupo para analisar os danos e impactos, aceitar responsabilidade e ponderar sobre as ações que seriam necessárias para a compensação. As sessões envolveram oficinas educacionais e módulos de treinamento sob a orientação de especialistas nos campos de segurança pública, violência sexual e de gênero, trauma, psicologia e aconselhamento, direito e direitos humanos, religião e resolução de conflitos. Além disso, participamos de oficinas educacionais de aprofundamento, com o objetivo de entender melhor a misoginia e a cultura do estupro, bem como a intervenção de terceiros. ${ }^{183}$

Constatou-se também que, a despeito das inúmeras críticas e da repercussão e pressão pública na mídia nacional e internacional, para resolução do caso de assédio, os representantes da Universidade apoiaram a escolha das alunas pelo processo restaurativo. Foi possível perceber que a existência do projeto-piloto e o comprometimento da Universidade com pesquisas e estudos acerca da Justiça Restaurativa deram suporte para tal posicionamento.

Pela análise realizada a partir dos aspectos indicados por George Pavlich, identifiquei o cuidado com as chamadas "governamentalidades restaurativas" através da preparação do contexto de acolhimento de todos os alunos e alunas pelos facilitadores, desde a fase inicial do processo (pré-círculo) até a realização do 'Dia de Aprendizado'. Foram estabelecidos princípios conjuntamente com todos os participantes do processo restaurativo. Houve atenção com a linguagem utilizada, sem rotulações das pessoas como vítimas ou ofensores. Foi instituído um grupo de

\footnotetext{
${ }^{183}$ Tradução livre da autora. No original: Through the restorative justice process we are doing the work required to be sorry - to confront the harms we have caused, to accept our responsibility, to figure out what is needed of us to make things right, and to gain the knowledge, skills and capacities to be trusted healthcare professionals. This is difficult and time consuming work - and it should be. We are committed to seeing this through. The process has engaged individuals from the faculty, university, the profession and the public. Involvement from these groups will continue and expand as the process moves to further examine the broader circumstances, causes and consequences of this situation. We have already learned much about ourselves, the consequences of our actions, and our contribution to the culture and climate within the faculty and the university. Our work has included: providing detailed accounts of our participation in the Facebook group and events following its discovery as part of the investigation; regular contact with the restorative facilitators since December (at a minimum weekly, in many cases daily); participation in regular and ongoing meetings with facilitators individually, in small groups and with the entire group to explore harms and impacts, accept responsibility and consider what actions are necessary to make amends. Sessions have included educational workshops and training modules supported by experts in the fields of public safety and security, sexualized and gendered violence and trauma, psychology and counselling, law and human rights, religion, and conflict resolution. In addition, we have taken specific in depth educational workshops to better understand misogyny and rape culture and bystander intervention.
} 
conselheiros externos para prestar supervisão e consultoria ao longo do processo restaurativo.

Concluo este trabalho com a percepção de que as constatações feitas acima e os resultados satisfatórios com relação ao processo restaurativo no caso de assédio da Faculdade de Odontologia, decorrem do fato dessa experiência ter sido realizada fora do contexto do poder judiciário, e pelo fato de fazer parte de uma instituição comprometida com pesquisas e práticas da Justiça Restaurativa. Além de estar situada na província da Nova Escócia, reconhecida como líder internacional em Justiça Restaurativa, com abordagens restaurativas nas áreas de educação e direitos humanos. Isso facilitou o desenvolvimento de formas de pensar a Justiça Restaurativa, descoladas da racionalidade punitiva que prevalece nas instituições, especialmente dentro do sistema de justiça. 
REFERÊNCIAS

AGUIAR, C. Z. B. Mediação e justiça restaurativa: A humanização do sistema processual como forma de realização dos princípios constitucionais. São Paulo: Quartier Latin, 2009.

ALMEIDA, G. A. DE. Conflitos interpessoais, constituição do sujeito de direito e promoção dos direitos humanos. No prelo, 2013.

ALMEIDA, G. A. DE (Orgs). O direito internacional dos refugiados: uma perspectiva brasileira. Rio de Janeiro: Editora Renovar, 2001.

ALMEIDA, G. A. DE. A proteção da pessoa humana no direito internacional: conflitos armados, refugiados e discriminação racial. São Paulo: Editora Clã Cultural, 2018.

ALVES, M. A. Pedagogia da alteridade: o ensino como acolhimento ético do outro e condição crítica do saber em Levinas. (Tese de doutorado) Pelotas: Universidade Federal de Pelotas - UFPEL, 2011.

ANDERSON, L. Introdução ao estudo do projeto piloto de justiça restaurativa da Dalhousie University. São Paulo/Halifax: Conversa informal realizada com Carla Maria Zamith Boin Aguiar, realizada em 7 jun. 2016.

ARTHUR, P. Como as "transições" reConfiguraram os direitos humanos: uma história ConCeitual da justiça de transição. In: REÁTEGUI, F. (org). Justiça de transiçãa - manual para a América Latina. Brasília: Ministério da Justiça; Nova York: ICTJ, 2011.

AYTO, J. Dictionary of word orgins. Bloomsburry, 1993.

BAZEMORE, S.; SCHIFF, G.; SCHIFF, M. Restorative community justice: repairing harm and transforming communities. Cincinnati-OH: Anderson Publishing, 2001.

BAZEMORE, S.; SCHIFF, M. Paradigm Muddle or Paradigm Paralysis? The Wide and Narrow Roads to Restorative Justice Reform (or, a Little Confusion May Be a Good Thing). Contemporary Justice Review. Vol. 7, No. 1, March 2004, pp. 37-57.

BEAGAN, B. Micro inequities and everyday inequalities: "race," gender, sexuality and class in medical school. In: Can J Sociol. 2001; 26(4): 583-610.

BELLUCK, P. Ações para evitar assédio na universidade falharam e precisam mudar, diz relatório. In: Folha de São Paulo. São Paulo, 14/06/2018. Publicado originalmente no The New York Times. Disponível em https://www1.folha.uol.com.br/ciencia/2018/06/acoespara-evitar-assedio-na-universidade-falharam-e-precisam-mudar-diz-relatorio.shtml. Acesso em $24 / 11 / 2018$.

BOBBIO, N. A era dos direitos. Tradução de Carlos NelsonCoutinho. Rio de Janeiro: Campus, 1992.

BRAITHWAITE, J. Crime, shame and reintegration. Nova York: Cambrigde University Press, 1989.

BRAITHWAITE, J. Restorative justice and responsive regulation. Oxford: Oxford University Press, 2002. 
BUTLER, J. Gender trouble: feminism and the subversion of identity. New York: Routledge, 1990.

CHRISTIE, N. Conflicts as Property. The British journal of criminology, Volume 17, Issue 1, 1 January 1977, Pages 1-15.

CLAIRMONT, D. Violence and public safety in the Halifax regional municipality. A report to the mayor as a result of the roundtable. Halifax: Atlantic Institute of Criminology, 2008.

CLAIRMONT, D. Moving on to the University: An assessment of the Dalhousie restorative justice pilot project. Halifax: Atlantic Institute of Criminology, Dalhousie University, 2015.

COMPARATO, F. K. A afirmação histórica dos direitos humanos. $8^{\mathrm{a}}$. Ed. São Paulo: Saraiva, 2013.

CORRÊA, A. Nos EUA,mais de 80 universidades são investigadas por ignorar estupros. In: Portal BBC News. Winston-Salem-EUA, 24/11/2014. Disponível em: https://www.bbc.com/portuguese/noticias/2014/11/141118_estupros_universidades_eua_ac Acesso em: 16/12/2018.

CUNNEEN, C. Reviving restorative justice traditions? In: JOHNSTONE, G.; VAN NESS, D. W. (Eds.). Handbook of restorative justice. London: Willan, 2007.

CURTIS, J.; HARRISON; L. Beneath the surface: Collaboration in alcohol and other drug treatment. An analysis using Foucault's three modes of objectification. J Adv Nurs, 2001;34(6): 737-744.

DEAN, M. Governmentality: power and rule in modern Society. London: Sage Publications, 1999. 51p.

DELEUZE, G.; GUATTARI, F. O que é a Filosofia? Rio de Janeiro: Editora 34, 1996.

DELEUZE, G.; GUATTARI, F. Mil platôs: capitalismo e esquizofrenia. Vol. 3 ed. Rio de Janeiro: Editora 34, 2004.

DHNET. Manifesto 2000 UNESCO (Cultura da paz). Disponível em:

http://www.dhnet.org.br/direitos/bibpaz/textos/m2000.htm

ESPOSITO, R. Communitas: The Origin and Destiny of Community. Stanford-CA:

Stanford University Press, 2010.

DURKHEIM, E. O individualismo e os intelectuais. Edição bilingue e crítica. (Marcia Consolim, Márcio de Oliveira, Raquel Weiss [orgs.]). São Paulo: Editora da Universidade de São Paulo, 2016.

EXECUTIVE Summary. Disponível em: $<$ https://www.dal.ca/content/dam/dalhousie/pdf/cultureofrespect/RJ2015-Summary.pdf $>$. Acesso em: 29/5/2016.

FARIELLO, Luiza de Carvalho. Brasil tem papel crucial no avanço da Justiça Restaurativa, diz especialista. In: Portal CNJ. 09/11/2015. Disponível em: http://www.cnj.jus.br/noticias/cnj/80864-brasil-tem-papel-crucial-no-avanco-da-justica- 
restaurativa-diz-especialista, acesso em 20/11/2018.

FOUCAULT, M. The subject and power. Crit Inq. 1982; 8(4): 777-795.

FOUCAULT, M. Vigiar e punir: nascimento da prisão. Petrópolis: Vozes, 2005.

FOUCAULT, M. 2004. Sécurité, territoire, population: Cours au Collège de France, 1977-1978. Paris, Gallimard/ Seuil, 435 p.

FOUCAULT, M. La hermenéutica del sujeto: curso en el Collège de France, 1981-1982. México: Fondo de Cultura Económica, 2002.

FREITAS JR., A. R. DE (Coord.). Contribuição da ciência política para um conceito operativo de conflito e uma pragmática responsável da mediação. In: SERAU JR., M. A.. (Org.) Mediação e direitos humanos: temas atuais e controvertidos. São Paulo: LTr, 2014.

FROESTAD, J.; SHEARING, C. D. Prática da Justiça - O modelo zwelethemba de resolução de conflitos. In: SLAKMON, C., DE VITTO, R. e PINTO, R. G. (Orgs.) Justiça

restaurativa. Brasília: DF, Ministério da Justiça - Programa das Nações Unidas para o Desenvolvimento, 2005, pp. 79-124.

FROESTAD, J.; SHEARING, C. D. Conflict resolution in South Africa: A case study (April 3, 2007). In : JOHNSTONE, G.; VAN NESS, D. W. (Eds.). Handbook of restorative justice. Londres: Willan, 2007.

GLUCKMAN, M. The ideas in Barotse Jurisprudence. New Haven, CT: Yale, University Press, 1965.

GIBBS, J. The Kpelle Moot: A therapeutic model for the informal settlement of disputes in Africa, 1-11, 1963.

GRINOVER, A.; WATANABE (Coord.), K.; CATÃO; CRONEMBERGER, L.F.; CAPPANARI, S. (Orgs.). Mediação no judiciário: desafios e reflexões sobre uma experiência. Rio de Janeiro: Forense, 2012.

HATFIELD, G. René Descartes. In: ZALTA, E. N. (Ed.) The Stanford Encyclopedia of Philosophy. Summer 2018 Edition. Disponível em: https://plato.stanford.edu/archives/sum2018/entries/descartes/.

HAYDEN, A.; HENDERSON, P. Victims: The invisible people. In: Consedine, J.; Bowen, H. Restorative justice: contemporary themes and practice. Lyttelton, N.Z. : Ploughshares Publications, 1999.

HOYLE, C. Policing and restorative justice. In: JOHNSTONE, G.; VAN NESS, D. W. (Eds.). Handbook of restorative justice. London: Willan, 2007.

IG São Paulo. Após 173 denúncias de abuso sexual em 2017, Cambridge admite ter "problema". 06/02/2018. Disponível em: https://ultimosegundo.ig.com.br/mundo/2018-0206/assedio-sexual-universidade-cambridge.html. Acesso em: 18/12/2018.

JACCOUD, M. Princípios, tendências e procedimentos que cercam a justiça restaurativa. In: GOMES, R. S. (Orgs.). Justiça restaurativa: coletânea de artigos. Brasília: Ministério da Justiça e Programa das Nações Unidas para o Desenvolvimento, 2005. 
JOHNSTONE, G. A. Restorative justice reader: Texts, sources, context. Londres: Willan, 2003.

JOHNSTONE, G.; VAN NESS, D. W. The meaning of restorative justice. In: JOHNSTONE, G.; VAN NESS, D. W. (Eds.). Handbook of restorative justice. Londres: Willan, 2007a.

JOHNSTONE, G.; VAN NESS, D. W. Conflict Resolution in South Africa: A Case Study. In: JOHNSTONE, G.; VAN NESS, D. W. (Eds.). Handbook of restorative justice. London: Willan, 2007b.

JOHNSTONE, G.; VAN NESS, D. W. The International development of restorative justice. In: JOHNSTONE, G.; VAN NESS, D. W. (Eds.). Handbook of restorative justice. Londres: Willan, 2007c.

JOHNSTONE, G.; VAN NESS, D. W. The future of restorative justice. In: JOHNSTONE, G.; VAN NESS, D. W. (Eds.). Handbook of restorative justice. Londres: Willan, 2007c.

JORNAL USP, 28/09/2018. Disponível em: https://jornal.usp.br/artigos/violencia-sexualna-usp-mito-exagero-ou-realidade/.Acesso em:16/12/2018.

KARP, D. R.; DRAKULICH, K. M. Minor Crime in a Quaint Setting: Practices, Outcomes, and Limits of Vermont Reparative Probation Boards. Criminology \& public policy, v. 3, n. n. 4, p. 655-86, 2004.

KELSEN, Hans. Teoria pura do direito. São Paulo: Martins Fontes, $6^{\mathrm{a}}$ ed ,2000.

LLEWELLY, J.; PHILPOTT, D. Restorative justice, reconciliation, and peacebuilding. Oxford: Oxford University Press, 2014.

LLEWELLYN, J.; DEM-SEY, A.; SMITH, J. An Unfamiliar Justice Story: Restorative Justice and Education Reflections on Dalhousie's Facebook Incident. Our Schools/ Our Selves, vol. 25, outono de 2015.

LEWELLYN, J.; MACISAAC, J.; MACKAY, M. Report from the restorative justice process. Dalhousie Univerty Faculty of Dentistry, May 2015.

LLEWELLYN, J. Restorative justice has more to offer than just diverting people from the criminal justice system. It's a powerful way of thinking that can reshape justice. In: Policy options politiques. 02/05/2018. Disponível em: http://policyoptions.irpp.org/magazines/may-2018/realizing-the-full-potential-of-restorativejustice/ Acesso em: 06/12/2018.

LYOTARD, J. F. Moderns et après - Les immatériaux. Paris: Autrement, 1985.

MARSHAL, T. Restorative justice: An overview. Londres: Home Office Research and Development Statistics Directorate, 1999.

McCOLD, P.; WACHTEL, T. Restorative justice theory validation. In: WEITEKAMP, E. G. M.; KERNER, H.-J. (Eds.). Restorative justice: theoretical foundations. Cullompton: Willan, 2002.

McCOLD, P. Paradigm muddle: the threat to restorative justice posed by its merger with community justice. Contemporary Justice Review. Vol. 7, No. 1, March 2004, pp. 13-35. 
MCCOLD, P. Paradigm muddle: the threat to restorative justice posed by its merger with community justice. Publicação on-line: 25 jan. 2007. Contemporary justice review: issues in criminal, social, and restorative justice. Disponível em: $<$ http://www.tandfonline.com/loi/gcjr20> Acesso em 27 dez. 2018.

McCOLD, P. What is the role of community in restorative justice theory and practice? In: ZEHR, H.; TOEWS, B. (Orgs.). Critical issues in restorative justice. New York: Criminal Justice Press, 2004, p. 155-171.

MIDGLEY, M. A presença dos mitos em nossas vidas. São Paulo: UNESP, 2014.

MORIN, E. A cabeça bem-feita: repensar a reforma, reformar o pensamento. Rio de Janeiro: Bertrand Brasil, 2003, 8 a ed.

NANCY, J. Being singular plural. Stanford-CA: Stanford University Press, 2000a.

NANCY, J. The speculative remark. Stanford-CA: Stanford University Press, 2000b.

O GLOBO. "Estudo mostra que metade dos universitários sofreu assédio sexual na Austrália". 01/08/2017. Disponível em: https://oglobo.globo.com/sociedade/estudo-mostraque-metade-dos-universitarios-sofreu-assedio-sexual-na-australia-21654156. Acesso em: $17 / 12 / 2018$.

PAVLICH, G. Derrida's ethics: Host, parasite and justice. (Invited Address), Department of Sociology, Dalhousie University, 1st February, 2002.

PAVLICH, G. Governing paradoxes of restorative justice. Londres: Glass House Press, 2005.

PAVLICH, G. Towards an ethics of restorative justice. In: WALGRAVE, L. (Ed.) Restorative justice and the law. Portland: Willan Publishing, 2002, pp. 1-18.

PAVLICH, G. Promised communities and unrestored justice. In: AERTSEN, I.; PALI, B. (Eds). Critical restorative justice. Oxford: Hart Publishing, 2017, pp 297-313.

PRANIS, K. Justiça restaurativa: revitalizando a democracia e ensinando a empatia. In: SLAKMON, C.; MACHADO, M. R.; BOTTINI, P. C. (Orgs.). Novas direções na governança da justiça e da segurança. Brasília: Ministério da Justiça - Secretaria da Reforma do Judiciário, 2006.

PUCCI, R. Criminalidade ambiental transnacional. Desafios para a sua regulação jurídica. São Paulo: Tese de Doutorado apresentada à FD-USP, 2012.

RESOLUÇÃO 2002/12 da ONU - Princípios básicos para utilização de programas de justiça restaurativa em matéria criminal. Disponível em: $<$ http://www.justica21.org.br/j21.php?id=366\&pg $=0 \% 22 \quad \% 5 \mathrm{Cl}$ \%22.Vuaxt5MrLVo\#.V4QSRrgrLIV>. Acesso em: 14 nov. 2015.

RESTORATIVE Justice Project. Disponível em: <http://www.dal.ca/campus_life/safetyrespect/student-rights-and-responsibilities/where-to-get-help/student-disputeresolution/restorative-justice-project.html>. Acesso em: 29 maio 2016.

RICOEUR, P. La mémoire, l'histoire, l'oubli. Paris: Éditions du Seuil, 2000. 
RICOEUR, P. O perdão pode curar? In: HENRIQUES, F. (Org.). Paul Ricoeur e a simbólica do mal. Porto: Edições Afrontamento, 2005.

SALM, J. L. New perspectives in public administration. A political process of education and leadership through mediation. Administrative theory \& praxis, v. September, ${ }^{0} 3$, p. 43844, 2009.

SALM, J. L.; STOUT, M. What restorative justice might learn from administrative theory. Contemporary Justice Review. Vol. 14, No. 2, June 2011, 203-225.

SCHROCK, D; SCHWALBE, M. Men, masculinity, and manhood acts. In: Annu Rev Sociol. 2009, 35(1): 277-295.

SKEAT, W. W. The concise dictionary of English etymology. Wordsworth Editions, 1993.

SKELTON, A. Africa. In: JOHNSTONE, G.; VAN NESS, D. W. (Eds.). Handbook of restorative justice. Londres: Willan, 2007.

SKOTNICKI, A. How is justice restored? Studies. In: Christian Ethics 19.2, 2006, pp. 187204.

STRANG, H.; BRAITHWAITE (Eds.). Restorative justice in civil society. Cambridge University Press, 2001.

SUPIOT, A. Homo Juridicus: Essai sur la fonction antrophologique du Droit. Paris: Éditions du Seuil, 2005.

TONCHE, J. A construção de um modelo 'alternativo' de gestão de conflitos: usos e representações de justiça restaurativa no Estado de São Paulo. (Tese de doutorado). São Paulo: FFLCH-USP, 2015.

UMBREIT, M. S. Restorative justice through victim-offender mediation: A multi-site assessment. Disponível em: $<\mathrm{http} / / /$ www.westerncriminology.org/documents/WCR/v01n1/Umbreit/umbreit.html $>$.Acesso em: 18 out. 2015.

UMBREIT, M. S. Restorative justice through victim offender mediation: A multi-site assessment. Western criminology review, 1(1), 1998. Disponível em: http://wcr.sonoma.edu/v1n1/schiff.html

VAN NESS, D.; STRONG, K. H. Restoring justice. An introduction to restorative justice. Londres e Nova York: Routledge Taylors \& Francis Group, 2015, $5^{\mathrm{a}} \mathrm{ed}$.

ZEHR, H. Changing lenses: A new focus for crime and justice. Scottdale: Herald Press, 1990.

ZEHR, H. The little book of restorative justice. Intercourse: Good Books, 2002. 


\title{
APÊNDICE A
}

\author{
Uma declaração pública dos Participantes do Processo de Justiça \\ Restaurativa da Dalhousie da Abordagem de Danos Relacionados aos Posts do \\ Grupo de Facebook dos Alunos de Odontologia da Dalhousie (DDS2015), \\ publicados em $1^{\circ}$. de março de 2015.
}

Nós, os 29 membros da classe DDS2015 que participam do processo de justiça restaurativa, apresentamos esta atualização para partilhar algumas informações sobre o processo e nossa experiência até o momento. Esta declaração reflete nossa experiência e impressões coletivas. Ela é dividida de modo a oferecer algumas reflexões obtidas diretamente de participantes do grupo de Facebook envolvidos em nosso processo, das mulheres que sofreram o impacto direto do incidente e que integram o processo de justiça restaurativa, assim como de todo o grupo de participantes. Nosso processo inclui 12 membros do grupo de Facebook DDS2015, seis mulheres nominadas nos posts que vieram a público e 11 mulheres e homens da turma da DDS2015 diretamente afetada.

Prestamos esta declaração neste momento, pois estamos na expectativa de um posicionamento do Comitê de Classe para Normas Acadêmicas (ASCC). O ASCC vem sendo informado sobre o trabalho no âmbito do processo restaurativo com vistas à reparação da conduta e ao tratamento dos danos relacionados ao incidente. Queremos partilhar algumas dessas informações com a comunidade em sentido mais amplo e com o público, para que todos possam também entender nossas perspectivas e experiências neste processo.

\section{Dos Membros do Grupo de Facebook da DDS2015 no Processo de Justiça Restaurativa}

Desde o início deste processo em dezembro, sentimo-nos extremamente arrependidos e assumimos a autoria do que fizemos (individualmente e em grupo). Nossa conduta como membros do grupo de Facebook foi ofensiva, cruel e injusta. Seu impacto propagou-se a nossos colegas de classe, amigos, familiares, faculdade, funcionários, pacientes, a comunidade universitária, a profissão e o público. Nossas 
ações desencadearam consequências não apenas para nós, mas também para terceiros. Muitas das consequências que sentimos tanto pessoal como profissionalmente são um resultado esperado de nossas ações, e admitimos nossa responsabilidade por essas consequências. Nossas ações tiveram um efeito profundo em outros, o que reconhecemos e lamentamos profundamente. Temos consciência de que nossa conduta rompeu o vínculo de confiança em muitas relações importantes. Sabemos que teremos de trabalhar para a reconquista dessa confiança. Desde dezembro, estamos nos dedicando ao processo intenso e complexo de autorreflexão e desenvolvimento necessário para iniciar o caminho de reconstrução da confiança de nossos colegas, familiares, professores, da comunidade universitária, da profissão e do público. Será uma longa jornada, porém trabalharemos todos os dias para modelar os valores pessoais e profissionais fundamentais aos quais estamos vinculados - e que nortearão nossa conduta agora e no futuro. Esperamos poder um dia readquirir a confiança daqueles que magoamos e ofendemos.

Nosso silêncio vem sendo interpretado por alguns como covardia - como se estivéssemos nos evadindo de nossas responsabilidades. Sentimo-nos tentados a ceder à pressão por pedidos de desculpas. Fazê-lo aplacaria nosso arrependimento, porém seria agir somente em interesse próprio, caso nossa atitude não fosse amparada no árduo trabalho exigido para adquirir a profundidade de entendimento inerente a um pedido sincero e profundo de desculpas. Comprometemo-nos a continuar trabalhando durante o processo restaurativo para desenvolver essa compreensão. Sabemos que será necessário muito mais que dizer 'lamento'. Estamos seriamente empenhados em descobrir um genuíno sentimento de pesar. Devemos desculpas sinceras primeiramente àqueles que prejudicamos de forma mais direta. Ao longo de todo este processo, já tivemos a oportunidade de expressar alguns desses pedidos de perdão, que foram aceitos. Continuamos trabalhando para merecer essa aceitação. Somente depois de termos avançado mais nesses esforços, estaremos prontos para apresentar pedidos de desculpas mais abrangentes ao público e à comunidade.

Em todo o processo restaurativo, estamos realizando trabalho necessário para lamentar com sinceridade, confrontar os males que causamos, aceitar nossa responsabilidade e descobrir o que é preciso para que possamos nos corrigir e angariar o conhecimento, habilidades e capacidade de despertar confiança como 
profissionais de saúde. Essa é uma tarefa custosa e longa - e é assim que deve ser. Assumimos o compromisso de vê-la concluída. O processo envolveu membros da faculdade, da universidade, da profissão e do público. O envolvimento desses grupos prosseguirá e o ampliaremos à medida que o processo avance, de modo a examinar em detalhes as circunstâncias, causas e consequências mais abrangentes desta situação. Já aprendemos muito sobre nós mesmos, os resultados de nossas ações e nossa contribuição para a cultura e o ambiente na faculdade e na universidade. Nosso trabalho envolveu: a prestação de contas detalhadas de nossa participação no grupo do Facebook e nos eventos que se seguiram à sua revelação como parte do contato regular com os facilitadores restaurativos desde dezembro (pelo menos uma vez por semana e, em muitos casos, diariamente), participação em reuniões periódicas e contínuas com os facilitadores individualmente, em pequenos grupos e com todo o grupo para analisar os danos e impactos, aceitar responsabilidade e ponderar sobre as ações que seriam necessárias para a compensação. As sessões envolveram oficinas educacionais e módulos de treinamento sob a orientação de especialistas nos campos de segurança pública, violência sexual e de gênero, trauma, psicologia e aconselhamento, direito e direitos humanos, religião e resolução de conflitos. Além disso, participamos de oficinas educacionais de aprofundamento, com o objetivo de entender melhor a misoginia e a cultura do estupro, bem como a intervenção de terceiros.

Não sabemos quais serão os resultados deste processo, pois este trabalho ainda está em curso. Temos consciência de que é impossível voltar atrás e desfazer o que aconteceu, porém temos o compromisso de tornar este incidente uma matéria importante - de forma a contribuir com a mudança necessária. A premência de mudança em nós mesmos ficou muito evidente em reflexões profundas sobre nossas falhas e ações deletérias. Também reconhecemos estar face à face com uma oportunidade e com a responsabilidade de contribuir para as mudanças necessárias no ambiente e na cultura em nossa faculdade, na comunidade universitária e na profissão da qual aspiramos participar um dia. Estamos empenhados em retribuir e prestar uma contribuição positiva para nossas comunidades. Por meio do processo de justiça restaurativa, temos a oportunidade de enfrentar o que fizemos e o mal que isso causou, além de aprender o que precisamos para nos tornar os profissionais de confiança que queremos ser. Estamos muito gratos pelo empenho de tempo, 
especialização e suporte que permitiu que isso se materializasse. Não pouparemos esforços para fazer jus a esta oportunidade e para retribuir à comunidade na mesma medida.

\section{Das Mulheres da Classe DDS2015 envolvidas no Processo de Justiça Restaurativa}

$\mathrm{Na}$ condição de mulheres diretamente afetadas pelos posts no Facebook divulgados para a mídia, decidimos participar deste processo de justiça restaurativa como um meio de abordar a conduta danosa revelada pelos posts e nossas experiências com a cultura mais ampla que refletem dentro de nossa faculdade, universidade e sociedade. Respeitamos a ideia de que cada pessoa prejudicada por esta situação tenha a mesma oportunidade de seguir adiante na direção com a qual se identificar. Queremos ser dignas de igual respeito por este caminho da justiça que escolhemos. Fizemos esta escolha com conhecimento de todas as opções que nos estavam disponíveis, tendo chegado à nossa decisão de maneira independente e não coercitiva. Fomos comedidas nas discussões de nossa perspectiva na mídia, porém para deixar claro -, não identificamos na cobertura da mídia social e da grande mídia a representatividade de nossas experiências únicas ou comuns. Várias pessoas (algumas bem-intencionadas) falaram sobre nós e, no processo, frequentemente tentaram se dirigir a nós em formas que consideramos ofensivas, silenciadoras e rememorativas do trauma. Por vezes não honraram nem confiaram em nossa perspectiva e decisão de prosseguir com este processo, as quais foram descartadas ou criticadas com base em decisões ou perspectivas de outrem. Somos profissionais formadas, de educação sólida, com preparadas o suficiente para explicar com palavras próprias o que estamos vivenciando e como queremos agir. Tomamos decisões individuais e conjuntas de usar as palavras cuidadosa e seletivamente em público, evitando acrescentar mais combustível para o escândalo deflagrado pela mídia, que já foi extremamente doloroso para nós. Algumas das táticas políticas e debates relacionados a esta situação tornaram desafiadora a decisão de seguir adiante com o processo de justiça restaurativa da maneira que desejávamos, e esses fatores externos foram responsáveis por novos danos. Aqui e ali, o volume da opinião pública sufocou nossas vozes quando queríamos expressar o que precisamos e 
queremos nesta situação. Acreditamos, por exemplo, que nossas visões não foram cruciais no processo de decisão de segregar os membros da nossa classe sabidamente envolvidos nos posts do Facebook. Ainda que essa decisão possa ter satisfeito as necessidades e interesses de outrem, foi inócua para nós por não ter instilado nenhum senso de segurança ou respeito. Ao contrário, nos fragmentou e alienou justamente quando mais precisávamos de apoio da comunidade de nossa classe. Muitos alegaram que todas as mulheres se sentem inseguras, porém esse não é o nosso caso - sentimo-nos seguras com os membros do grupo do Facebook envolvido neste processo restaurativo.

O processo restaurativo abriu um espaço muito importante para que nos envolvêssemos, segura e respeitosamente, com nossos colegas e terceiros para transmitir nossas perspectivas e necessidades. O processo nos permite uma interação que respeita e valoriza nossas visões únicas e o nível de compromisso e conexão que desejamos. Além disso, ele nos permite abordar as questões sistêmicas e institucionais que influenciam o ambiente e a cultura em que vivemos e aprendemos. Queremos que este processo contribua significativamente para a introdução de uma mudança nessa cultura e esperamos poder contar com o respeito, o tempo e o espaço necessários para realizar esse trabalho.

\section{De todos os participantes da classe DDS2015 envolvidos no Processo de Justiça Restaurativa}

Estamos todos compromissados com o trabalho conjunto no âmbito do processo de justiça restaurativa para tratar questões específicas e mais amplas, assim como os danos relacionados ao grupo do Facebook. Em todo este processo, estamos tratando do incidente imediato em tela, ao mesmo tempo em que também investigamos os fatores contribuintes que nos fizeram chegar a este ponto como classe, faculdade e universidade. Esperamos que esta carta lance alguma luz sobre o nosso processo até o momento, naquilo que esperamos atingir e em alguns dos desafios que enfrentamos. Somos de opinião que a educação e perspectiva que estamos adquirindo por meio de nossa participação no processo de justiça restaurativa permitirão que nos tornemos melhores profissionais de saúde, colegas e representantes da Universidade Dalhousie. Como grupo, pedimos que nossa 
privacidade e nosso direito de prosseguir com este processo restaurativo fora da arena pública sejam respeitados. A constante atenção pública tem sido maléfica e até ameaçadora para nós, nossos familiares e amigos. Nós nos envolveremos com nossas comunidades e questões em sentido mais amplo ao longo do processo restaurativo, porém primeiramente precisamos seguir com nosso trabalho para entender e enfrentar os danos imediatos envolvidos. Esperamos que, ao longo desse processo, nossas vozes e experiências prestem uma contribuição significativa para as importantes discussões públicas acerca de sexismo, misoginia, inclusão e profissionalismo. 